\title{
RETROFLEXION IN NEPALI
}

\author{
Rajesh Khatiwada
}

Nepali, an Indo-Aryan language spoken in Nepal along with India and Bhutan, and some parts of Burma, possesses three coronal stops (2 plosives and 1 affricate). Retroflexion is traditionally considered as the distinctive feature between two different types of plosives. Though retroflexion in Nepali is considered- like in the case of other Indo-Aryan languages- a fundamental distinctive articulatory parameter (Bhat 1973, Ladefoged and Bhaskararao 1983, Ladefoged and Maddieson 1996), Pokharel (1989), however, claims that there is no retroflex category in Nepali, because the "so-called" (sic.) Nepali retroflex stops are not produced with the "tongue tip curling back" as it is described in the traditional grammar. In this work, I have tried to show that this claim is just one side of the story and that the "retroflex" as a phonetic and phonological category "does exist" in Nepali. Based on two different palatographic and linguographic studies (of 9 speakers four females and five males- of Nepal) I have presented a different scenario than that of Pokharel, without completely denying his claim.

Keywords: retroflexon, Nepali, palatography, linguography, apicality

1. Introduction

Although the Nepali grammatical tradition goes back to the $19^{\text {th }}$ century, very few explicit linguistic studies have been done since. Situation of phonetic and phonological study is very far from being satisfactory. Acoustic study of the Voice Onset Time (VOT) of Nepali stops done by Poon and Mateer seems to be the first instrumental work done in Nepali (Poon and Mateer 1985). The PhD dissertation of Pokharel comes next; his work embraces many different domains of Nepali phonetics and phonology (Pokharel 1989). Though Pokharel's articulatory data (palatography and x-rays) were based on a single speaker of Nepali, his work is a milestone of the experimental work opening different domains of study of Nepali phonetics and phonology. His experimental verifications are still valuable and important. He claimed that Nepali, unlike other Indo-Aryan languages does not possess retroflex but apico-alveolar type. The present work tries to verify this claim with the help of 9 native speakers.

Based on direct palatography and linguography method, this work's main goal is to study different places of articulation and lingual contact type of coronal stops of Nepali. Based on 9 speakers (5 males and 4 females), the present paper summarizes results from two different experimental works realized for a chapter of my $\mathrm{PhD}$ thesis defended in 2014 (Khatiwada 2017). The linguistic variety used in this study carried out in France is the standard Nepali spoken by the educated speakers whose first language is Nepali and who practice this language in their daily life in Nepal or in France.

This work based on articulatory data is descriptive without any particular theoretical 'pretention', the work however is based on the idea that phonological feature should be grounded on phonetic features (Clements 2006, 2009). Different phonetic realizations for the same phonological category are quite natural and expected.

Gipan 4. 2019. 19-29. 


\section{0 / Retroflexion in Nepali}

\section{Phonological inventory of Nepali consonants}

The table 1 below presents 27 phonologically contrastive consonants of standard Nepali spoken in Nepal (Bandhu et al. 1971, Pokharel 1989, Khatiwada 2009).

Table 1: 27 phonologically distinctive consonants of Nepali. Consonants from spelling pronunciation of Sanskrit borrowed words are not included in this list.

\begin{tabular}{|c|c|c|c|c|c|c|c|c|c|c|c|c|}
\hline & \multicolumn{2}{|c|}{ Bilabial } & \multicolumn{2}{|c|}{ Dental } & \multicolumn{2}{|c|}{ Alveolar } & \multicolumn{2}{|c|}{ Retroflex } & Palatal & \multicolumn{2}{|c|}{ Velar } & Glottal \\
\hline Plosive & $\begin{array}{l}\mathrm{p} \\
\mathrm{p}^{\mathrm{h}}\end{array}$ & $\begin{array}{l}\mathrm{b} \\
\mathrm{b}^{\mathrm{h}}\end{array}$ & $\begin{array}{l}\mathrm{t} \\
\mathrm{t}^{\mathrm{h}}\end{array}$ & $\begin{array}{l}d \\
d^{\mathrm{f}}\end{array}$ & & & $\begin{array}{l}\mathrm{t} \\
\mathrm{t}^{\mathrm{h}}\end{array}$ & $\begin{array}{l}\mathrm{d} \\
\mathrm{d}^{\mathrm{f}}\end{array}$ & & $\begin{array}{l}\mathrm{k} \\
\mathrm{k}^{\mathrm{h}}\end{array}$ & $\begin{array}{l}g \\
g^{f}\end{array}$ & \\
\hline Affricate & & & & & $\begin{array}{l}\text { ts } \\
\text { ts }\end{array}$ & $\begin{array}{l}\mathrm{dz} \\
\mathrm{dz}\end{array}$ & & & & & & \\
\hline Nasal & & $\mathrm{m}$ & & $\mathrm{n}$ & & & & & & & y & \\
\hline Tap or flap & & & & & & $\mathrm{r}$ & & & & & & \\
\hline Fricative & & & & & $\mathrm{s}$ & & & & & & & $\mathrm{f}$ \\
\hline Lateral & & & & & & 1 & & & & & & \\
\hline
\end{tabular}

The above list does not include consonants that we might find in some spelling pronunciation of Sanskrit borrowed words. All consonants, except the velar nasal $/ \mathrm{y} / \mathrm{can}$ occur in any syllabic position (though we find some onomatopoeic words starting with this phoneme at the beginning of a word as in yjar yjar or yur yur growling (Bandhu et al. 1971: 26). Only clusters $C^{l} C^{2}$ with glides (j and w) and rhotique (r) in the $C^{2}$ position are found in Nepali, though insertion of vowel epenthetic are often found in the case of $C^{l} r$. (for more information see Bandhu et al. 1971: 34-35).

Like other Indo-Aryan languages, Nepali has a contrastive series of retroflex stops $/ \mathrm{t} \mathrm{t}^{\mathrm{h}} \mathrm{d}$ $\mathrm{d}^{\mathrm{f}} /$ in addition to its dental and affricate alveolar stops. Though some linguists unconvinced by the presence of retroflex stops in Nepali use apical alveolar to define this series (Pokharel 1989), this work tries to show that this statement needs to be examined experimentally. With the help of direct palatography and linguography, I attempt to show that retroflex stops are present in Nepali though this does not involve higher degree of retroflexion like in other South Asian languages (Ladefoged and Bhaskararao 1983) and the Nepali retroflex consonants are not always phonetically "retroflexed". Different types of retroflexion along with the apical alveolar type consonants are regrouped inside a single phonological category, retroflex stops.

\section{Methodology}

Three different series of Nepali coronal stops were taken to study the production of these consonants. The articulatory data were taken using the direct palatography and the linguography method.

\subsection{Corpus}

Two corpora were used to determine the articulation configuration of the Nepali coronal stops. To avoid the coarticulation effect, the same vowels at both side of the studied consonant are used. In order to get the natural pronunciation, special attention was paid to the real words, but some logatoms (non-sense) words are equally used when no real 
words were found. The first corpus relates studying places of articulation of simple dental, affricate and retroflex consonants in function of their voice and aspiration features. For the first experiment, only [a] was used in two adjacent vocalic positions, $\left(C^{1}\right) \underline{V^{1}} \mathbf{C}^{2} \underline{V}^{2}$, where the $\mathbf{C}^{2}$ is the studied consonant. The 12 different consonants used in the first corpus are listed in table 2. It should be noted that the plosive voiced retroflex consonants $/ \mathrm{d} /$ and $/ \mathrm{d}^{\mathrm{h}} /$ are systematically produced as retroflex flap $[\mathrm{r}]$ and $\left[\mathrm{r}^{\mathrm{h}}\right]$.

Table 2: Corpus of first experience. $\mathrm{T}$ : voiceless unaspirated, $\mathrm{T}^{\mathrm{h}}$ : Voiceless aspirated, D: voiced unaspirated, $\mathrm{D}^{\mathrm{h}}$ : voiced aspirated

\begin{tabular}{|c|c|c|c|c|c|c|c|c|c|}
\hline & \multicolumn{3}{|c|}{ Dental } & \multicolumn{3}{|c|}{ Retroflex } & \multicolumn{3}{|c|}{ Affricate } \\
\hline $\mathrm{t}$ & $/ \mathrm{t} /$ & [mata] & mother & $/ \mathrm{t} /$ & [bata] & basin & $/ \mathrm{ts} /$ & [batsa] & promise \\
\hline $\mathrm{t}^{\mathrm{h}}$ & $/ \mathrm{t}^{\mathrm{h}} /$ & {$\left[\mathrm{mat}^{\mathrm{h}} \mathrm{a}\right]$} & forehead & $/ \mathrm{t}^{\mathrm{h}} /$ & [pat $\left.{ }^{\mathrm{h}} \mathrm{a}\right]$ & lambs & $/ \mathrm{ts}^{\mathrm{h}} /$ & [batsha] & calves \\
\hline $\mathrm{d}$ & $/ \mathrm{d} /$ & [ada] & half & $/ d /$ & [gara] & cart & $/ \mathrm{dz} /$ & [badza] & musical instrument \\
\hline $\mathrm{d}^{\mathrm{f}}$ & $/ \mathrm{d}^{\mathrm{f} /}$ & [bad $\left.{ }^{\mathrm{h} a}\right]$ & obstacle & $/ \mathrm{d}^{\mathrm{h} /}$ & [gar $\left.{ }^{\mathrm{i} a}\right]$ & dark & $/ \mathrm{dz}^{\mathrm{h}} /$ & [badz & logatom \\
\hline
\end{tabular}

The Second corpus (Table 3) was studied to examine whether there are coarticulation effects in function of three different major vowels namely $/ \mathrm{i} a \mathrm{u} /$. The purpose of this second corpus is to study the influence of the different vocalic context on the place of articulation and on lingual contact type. We have restricted the analysis to only the articulation of the robust consonantal position which is voiceless, unaspirated consonant, i.e. [t].

Table 3: Corpus of second experiment: $\mathrm{aCa}, \mathrm{iCi}$ and $\mathrm{uCu}$.

\begin{tabular}{|l|l|l|l|l|l|l|}
\hline & \multicolumn{2}{|l|}{ Dental } & \multicolumn{3}{l|}{ Retroflex } & Affricate \\
\hline$/ \mathrm{aCa} /$ & {$[\mathrm{mata}]$} & mother & {$[$ bata $]$} & basin & {$[\mathrm{batsa}]$} & promise \\
\hline$/ \mathrm{iCi} /$ & {$[\mathrm{miti}]$} & date & {$[$ miti $]$} & logatom & {$[\mathrm{mitsi}]$} & (she) pressed, (she) squeezed \\
\hline$/ \mathrm{uCu} /$ & {$[\mathrm{kutu}]$} & logatom & {$[$ mutu $]$} & heart & {$[$ mutsu $]$} & logatom \\
\hline
\end{tabular}

All words with the target consonants were embedded in the carrier phrase "babako " (Father's ), and were taken two times each.

\subsection{Participants}

Five ( 3 males and 2 females) and four ( 3 males and 1 female) participants with no articulatory and perceptive defects volunteered respectively in the first and second experiments. All experiments were done in Paris. Except for the two participants (F1 and M1) living in France for the last 20 years at the moment of study, all other participants were living in Nepal. They have never spent more than one year outside of Nepal and at the time of this study they were either visiting Paris or studying in Paris.

\subsection{Analysis and interpretation}

Direct palatography and linguography (Marchal 1988, Ladefoged 2003) were used to determine the information on the place of articulation and type of lingual contact of the studied consonant. Though old, direct palatography and linguography are still very useful and efficient methods for linguistic research. They are simple, economical, portable and informative to the linguist. Both palatograms (showing the area of the palate where the 


\section{2 / Retroflexion in Nepali}

tongue tip and surface make contact) and linguograms (showing the tongue contact during the articulation) were obtained by using a digital (video) camera. To take palatography, first we paint the tongue with the help of a small brush, a mixture of black substance prepared with charcoal, chocolate powder and edible oil; then we ask the participant to pronounce the word with the target consonant, and finally we put a small mirror inside the mouth to take the picture of the mark left by tongue contact on the palate. Direct linguography is just the opposite process to the palatography. Instead of painting the tongue tip and surface, this time we paint the palate with the mixture and take picture of the tongue with the mark of the mixture on the palate. Palatography is used as a cover term in this work for both methods.

Different methods exist to determine different articulatory zones. In the present work, the place of articulation is identified with reference to the dentition plan proposed by Firth (1948) with a slight modification on my part. Unlike Firth's original plan, mid-canine line is introduced between lateral incisor and canine line, reducing hence alveolar region (figure 1 left). The modified reduced alveolar zone corresponds to the alveolar zone proposed by Ladefoged and Maddieson (1996) where this zone denotes only the front part of the alveolar ridge. Table 4 summarizes the criteria which help us to define different places of articulation used in this work.

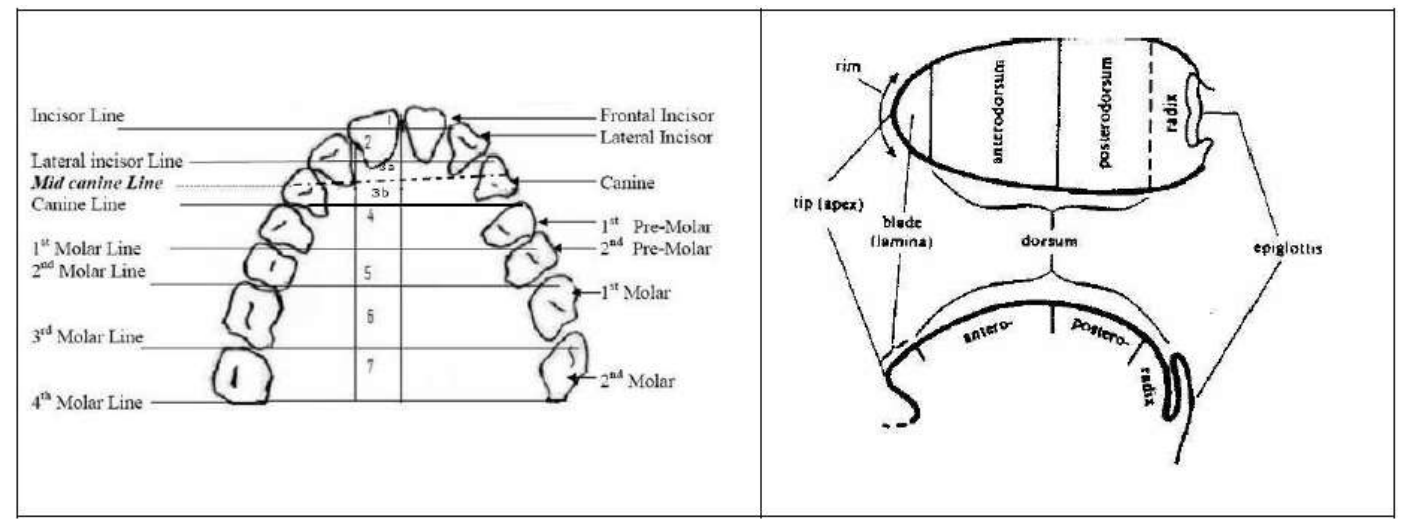

Figure 1: Reference lines and articulatory zones with a slight modification of Firth's dentition plan, with a new mid canine line (left) and subdivision of tongue proposed by Catford (right).

Concerning the lingual contact, this work is inspired by the lingual division proposed by Catford (1977) (Figure 1 right). As for the place of articulation, it is not easy to delimitate precisely the different frontier between the rim, tongue tip, tongue blade and tongue back. This study tried to be coherent and consistent during these interpretations.

Table 4: Different articulatory zones based on Firths original plan (see figure 1 (left))

\begin{tabular}{|l|l|l|}
\hline 1 & Incisor line & Dental \\
\hline $3 \mathrm{a}$ & Lateral incisor line + mid-canine line & Alveolar \\
\hline $1,2-3 \mathrm{a} / 3 \mathrm{~b}$ & Incisor + lateral incisor + mid-canine line & Dento-alveolar \\
\hline 4 & Mid-canine line + first molar & Post-alveolar \\
\hline
\end{tabular}


Khatiwada / 23

\begin{tabular}{|l|l|l|}
\hline 5 & $1^{\text {st }}$ molar $+2^{\text {nd }}$ molar & Pre- palatal \\
\hline 6 & $2^{\text {nd }}$ molar $+3^{\text {rd }}$ molar line & Palatal \\
\hline 7 & $4^{\text {th }}$ molar line & Velar \\
\hline
\end{tabular}

But giving alone the contact type does not inform much if we don't take in consideration the lingual configuration. If we consider the English [t] articulated at the alveolar ridge with tongue tip contact, as in ten [ten] $d \wedge s$ दस and Nepali [t], articulated by some Nepalese speakers at the same region with tongue tip, we don't have the same acoustic outcome. For a Nepali ear, the first [t] resembles more as Nepali [t] as in टिन [tin] tin than in तिन [tin] three. Though the two segments are defined phonologically as apico-alveolar these are not realized phonetically the same. The question is: what is that phonetic feature which differentiates these two different "apico-alveolar" segments?

It seems that the "apicality" does not have the same "features" in different languages. One can say that we are dealing with two different languages and the same features are not produced with the same phonetic output. Taking just these two parameters alone i.e. the place of articulation and the lingual contact is not sufficient to define appropriately these two types of sound which are treated as the same in the classical phonetic description (apico-alveolar). Lingual contact is not just an obstruction at the palate without any lingual configuration consideration as it is "considered" in classical phonetic descriptions (Léon 1992, Ladefoged and Maddieson 1996).

Following Hála (1964), it is important to underline that the tongue is indivisible, so when we are using parameters such as "apical" or "laminal", we cannot imagine just the tongue tip (apex) or the tongue blade raising and making obstruction against the palate. For Hála, one should conceive the notion of apical or laminal as the "predominance" of this part of the tongue rather than "just" this part of the tongue. He defines apical as a consonant formed "principally" with the tongue tip. Based on x-ray film of different apical consonant types, Hála observed that the tip of the tongue can create obstruction against the palate in three different ways: either horizontally, when the surface of the tongue body makes contact horizontally against the palate, or vertically by the extreme part of the tongue (the part which Catford called rim (figure 1 left)), or at the underneath of the tongue tip (sub-apical part), as we can see in the following original diagram presented by the author (figure 2).

Hála depicted three different types of apical [t] in different languages: the first type is the $[t]$ as in French, which he called "horizontal type" because the consonant is articulated by the back of the tongue making constriction against the upper palate horizontally (picture 1), the second type of apical $[t]$ is the English one where the articulation is of "vertical type of apical" which is formed by the extreme tongue tip or rim which creates the obstruction vertically against the alveolar ridge which Hála called cacuminal (figure 3.2). The last type of the apical is presented in figure 3.3, which is the Tamil retroflex consonant [t], where the tongue tip is applied vertically and it is retroflexed. 

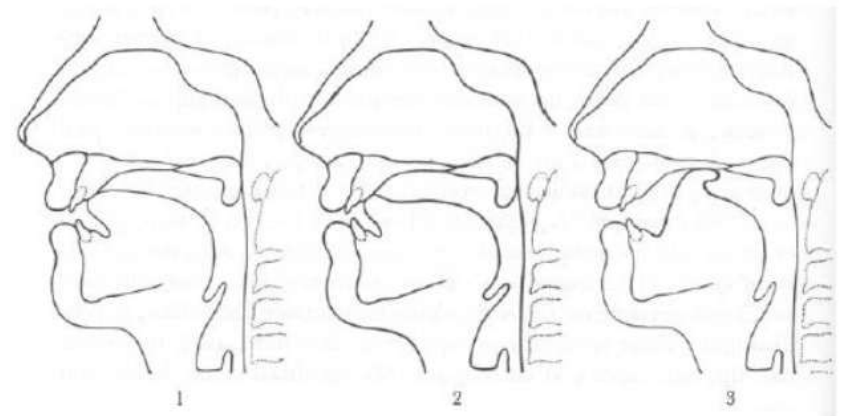

Figure 2: Three types of « apical » described by Hála, (1) "horizontal” type, like Czech or French $t,(2)$ "vertical” type like English $t$, and (3) "vertical retroflex" type like Tamil t (Hála 1964)

The present work is influenced by Hála's proposition which I found to be the most convincing analysis in the case of retroflex and dental consonants.

\section{Results and discussion}

\subsection{Experiment 1: stops in the function of voice and aspiration}

Though we did not find any major difference concerning the place of articulation and the lingual contact of the four different laryngeal types, the voiced aspirated and the voiced consonants show "lighter" contact than their counterpart i.e. the unaspirated and the aspirated voiceless consonants.

\section{a. Dental and affricate}

We have observed that all of our five participants use, to a certain extent, the same places of articulation and the same lingual type during the production of the simple dental and affricate production. Except for one participant M1, who systematically articulated his "simple dental category consonant" at the alveolar zone and affricates at the post-alveolar zone, all the other four participants show consistency on the production of dentals and affricates on the dental-alveolar zone. Concerning the lingual configuration, except M3, who seemed to use pure tongue tip (apical) contact, all the other four participants used the tongue blade to produce these two categories.

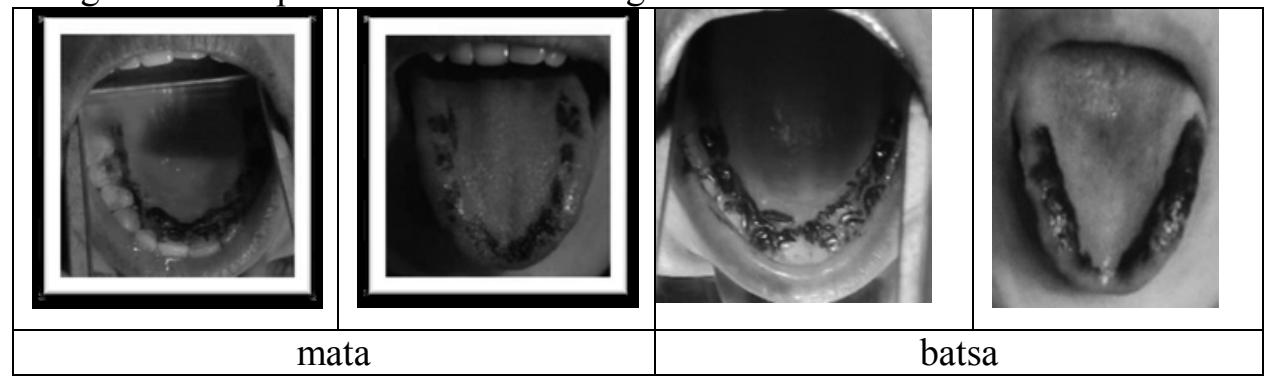

Figure 3: Palatograms and linguograms of mata (speaker F1) and batsa (speaker F2. Both words are typical examples of the dento-alveolar type produced with the blade of the tongue (laminal). 
Following table 5 summarizes the result of the first experiment of simple dentals and affricates:

Table 5: Results of dental and affricate stops of Nepali. PA : place of articulation, LC : Lingual contact, D: dental, DA: dento-alveolar, A: Alveolar, L: Laminal, Ap: Apical, AL: Apico-laminal, Pal: Post-alveolar

\begin{tabular}{|c|c|c|c|c|c|c|c|c|c|c|c|c|c|c|c|c|}
\hline & \multicolumn{2}{|l|}{$/ \mathrm{t} /$} & \multicolumn{2}{|l|}{$/ \mathrm{ts} /$} & \multicolumn{2}{|l|}{$/ \mathrm{t}^{\mathrm{h} /}$} & \multicolumn{2}{|l|}{$/ \mathrm{ts}^{\mathrm{h} /}$} & \multicolumn{2}{|l|}{$/ \mathrm{d} /$} & \multicolumn{2}{|l|}{$/ \mathrm{dz} /$} & \multicolumn{2}{|l|}{$/ \mathrm{d}^{\mathrm{f}} /$} & \multicolumn{2}{|c|}{$/ \mathrm{dz}^{\mathrm{f} /}$} \\
\hline LOC & PA & $\mathrm{LC}$ & PA & LC & PA & LC & PA & LC & PA & LC & $\mathrm{PA}$ & LC & PA & $\mathrm{LC}$ & PA & LC \\
\hline $\mathrm{F} 1$ & $\mathrm{DA}$ & $\mathrm{L}$ & $\mathrm{DA}$ & $\mathrm{L}$ & $\mathrm{DA}$ & $\mathrm{L}$ & $\mathrm{DA}$ & $\mathrm{L}$ & $\mathrm{DA}$ & $\mathrm{L}$ & $\mathrm{DA}$ & $\mathrm{L}$ & $\mathrm{DA}$ & $\mathrm{L}$ & $\mathrm{DA}$ & $\mathrm{L}$ \\
\hline F2 & $\mathrm{DA}$ & $\mathrm{L}$ & $\mathrm{DA}$ & $\mathrm{L}$ & $\mathrm{DA}$ & $\mathrm{L}$ & $\mathrm{DA}$ & $\mathrm{L}$ & $\mathrm{DA}$ & $\mathrm{L}$ & $\mathrm{DA}$ & $\mathrm{L}$ & $\overline{\mathrm{DA}}$ & $\mathrm{L}$ & $\mathrm{DA}$ & $\mathrm{L}$ \\
\hline M1 & A & $\mathrm{L}$ & $\mathrm{PA}$ & $\mathrm{L}$ & A & $\mathrm{L}$ & PA & $\mathrm{L}$ & A & $\mathrm{L}$ & $\mathrm{PA}$ & $\mathrm{L}$ & A & $\mathrm{L}$ & PA & $\mathrm{L}$ \\
\hline M2 & $\mathrm{DA}$ & $\mathrm{L}$ & $\mathrm{DA}$ & $\mathrm{L}$ & DA & $\mathrm{L}$ & $\mathrm{DA}$ & $\mathrm{L}$ & $\mathrm{DA}$ & $\mathrm{L}$ & $\mathrm{DA}$ & $\mathrm{L}$ & DA & $\mathrm{L}$ & $\mathrm{DA}$ & $\mathrm{L}$ \\
\hline M3 & $\overline{\mathrm{DA}}$ & $\mathrm{AL}$ & $\mathrm{DA}$ & $\mathrm{L}$ & $\mathrm{DA}$ & Ap & $\overline{\mathrm{DA}}$ & $\mathrm{L}$ & $\mathrm{D}$ & $\overline{A p}$ & $\mathrm{DA}$ & $\mathrm{L}$ & $\mathrm{D}$ & $\overline{A p}$ & $\overline{\mathrm{DA}}$ & $\mathrm{L}$ \\
\hline
\end{tabular}

\section{b. Retroflex}

Retroflex consonants in Nepali show a considerable number of variations during its production. These variations concern not only the place of articulation but also the type of tongue contact during the production. Though the post-alveolar zone is the more used place of articulation, we noticed the larger place of articulation zone from alveolar to prepalatal zone involved during its production.

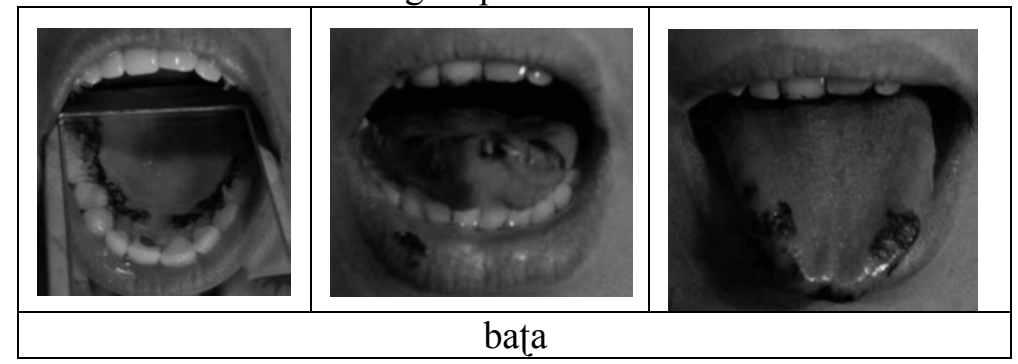

Figure 4: Palatogram (left) and linguograms for Speaker F1. Palatal contact is behind the alveolar ridge. The tongue tip and the rim without retroflexion are used. Type is the typical example of apico-alveolar type described by Pokharel (1989).

Following table 6 summarizes the articulatory strategy of the speakers about the use of the tongue contact and the place of articulation during the retroflex production. In this first study, we can observe that $75 \%$ of the productions are of the cacuminal type as against only $25 \%$ which are of the real retroflexion type.

Table 6: Summary, results of Retroflex. PA : place of articulation, LC : lingual contact, Post-Al: Post alveolar, C : cacuminal, SA : sub-apical

\begin{tabular}{|l|l|l|l|l|l|l|l|l|}
\hline & \multicolumn{4}{|l|}{$/ \mathrm{t} /$} & \multicolumn{1}{l|}{$/ \mathrm{d} /$} & \multicolumn{2}{l|}{$/ \mathrm{d}^{\mathrm{h}} /$} \\
\hline LOC & PA & LC & PA & LC & PA & LC & PA & LC \\
\hline F1 & Post-Al & C & Post-Al & C & Post-Al & C & Post-Al & C \\
\hline F2 & Post-Al & C & Post-Al & C & Post-Al & C & Post-Al & C \\
\hline M1 & Post-Al & C & Post-Al & C & Post-Al & C & Post-Al & C \\
\hline M2 & Post-Al & C & Post-Al & C & Post-Al & C & Post-Al & C \\
\hline M3 & Pre-pal & SA & Pre-pal & SA & Pre-pal & SA & Pre-pal & SA \\
\hline
\end{tabular}




\section{6 / Retroflexion in Nepali}

\subsection{Experiment 2: contextual influence}

The second experimentation shows less variation in the case of simple dentals and affricate consonants. But contrary to the first experience, the second one shows more retroflexed type during the production of the retroflex category. Very few cacuminal type consonants were found in the latter experience.

\section{a. Dental and affricate}

Simple coronal consonants which are defined as "dental" are produced with the blade of the tongue. Most of the dental consonants are produced in the large expanded zone that we can define as dento-alveolar. But we also find a variation of production inside this category a large spectrum of place of articulation. Though dento-alveolar productions are the most preferred type, some 'dental' types and 'alveolar' types are also found in this experiment making the spectrum larger for place of articulation for this category.

We also found variation in the case of lingual contact. Though laminal is the lingual contact type common during the production of the Nepali dentals, some "apical" type were also found during some dental production. One speaker produced the apico-laminal type creating a large contact.

The Nepali affricates are articulatorily a very stable class. In the second experiment as well as in first one, they are produced at the large dento-alveolar space. Table 7 summarizes the results of dental and affricate consonants of experiment 2.

\section{b. Retroflex}

Retroflexion showed an important variation during its production: both the place of articulation and the lingual contact types are affected by this variation. Our result of the second experiment shows that the post-alveolar region is the most "used" region during the production of the retroflex consonants (see Table 4). Only retroflex consonants pronounced in \#_iCi were produced systematically as the alveolar type. Some more posterior types such as pre-palatal, are also being observed among some participants. Compared to Pokharel's claim (Pokharel 1989), these posterior types are quite new and are similar to the traditional description of retroflex sounds in South Asian languages (Ladefoged and Bhaskararao 1983).

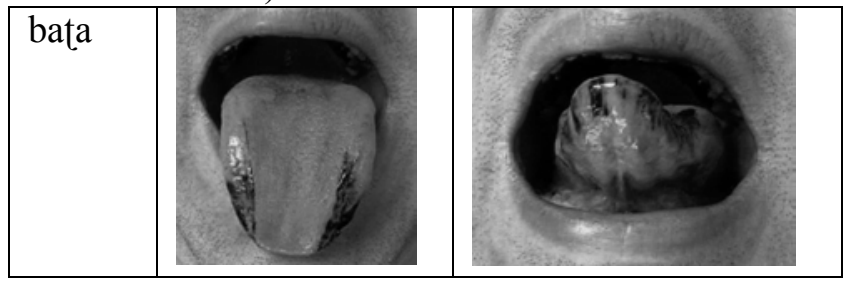




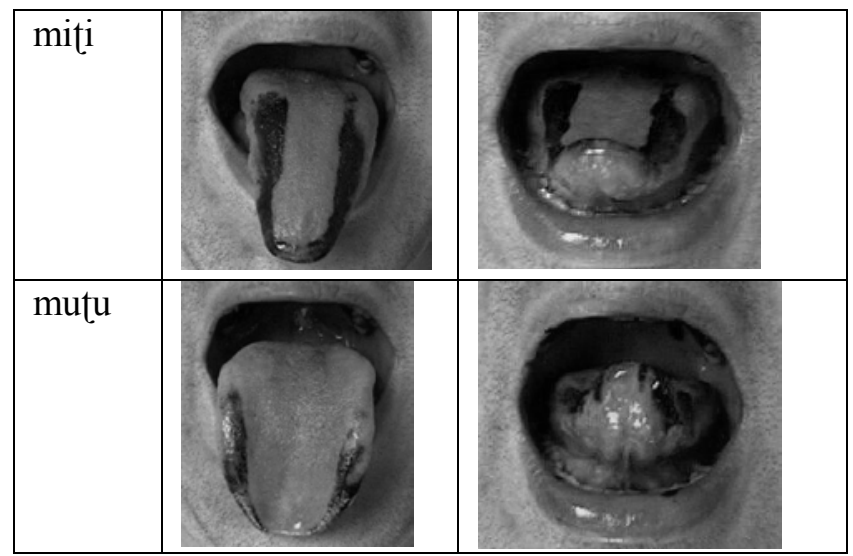

Figure 5 : Linguograms of Corpus 2 test words as produced by the speaker M4 in different vocalic contexts : bata, miti and mutu.

If a majority of participants of the first experience used the rim (tongue tip, see Catford 1977), we observed, in the second experience- especially during the production of $/ \mathrm{i} /$ and $/ \mathrm{u} /$ - the presence of more sub-apical contact i.e. tongue tip is retroflexed. Contrary to Pokharel who had claimed that Nepali does not possess any retroflex consonants but only apico-alveolar type (Pokharel 1989), our study found different types of lingual configuration and show that retroflex consonants do exist in Nepali.

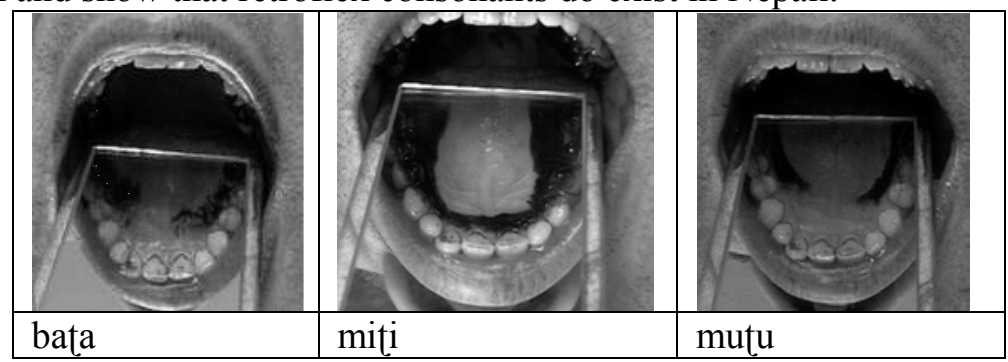

Figure 6: Palatograms of Corpus 2 test words as produced by the speaker M4 in different vocalic contexts: bata, miti and mutu. The high front vowel is realized further forward and with only the tip and the rim of the tongue without sub-apical (retroflexion) contact.

Our result however is not contradictory to Pokharel's result; instead, has tended to verify his claim adding more variation - thanks to more number of participants. Only the consonants pronounced with the front vowel [i] are produced more front type i.e. alveolar, otherwise those which were produced in the environment of [a] and [u], produced more generally as post-alveolar and as pre-palatal in some cases. Table 7 summarizes the result of our second experiment.

Table 7: Summary of results of three coronal category of Nepali

\begin{tabular}{|l|l|l|l|l|l|l|l|}
\hline LOC & Contexts & $/ \mathrm{t} /$ & & $/ \mathrm{ts} /$ & & $/ \mathrm{t} /$ & \\
\hline & & PA & LC & PA & LC & PA & LC \\
\hline & aCa & DA & L & DA & L & PP & SA \\
\hline
\end{tabular}


28 / Retroflexion in Nepali

\begin{tabular}{|l|l|l|l|l|l|l|l|}
\hline F3 & $\mathrm{iCi}$ & DA & L & DA & L & A & C \\
\cline { 2 - 8 } & $\mathrm{uCu}$ & DA & L & DA & L & Post-al & SA \\
\hline \multirow{3}{*}{ M4 } & $\mathrm{aCa}$ & DA & L & DA & L & Post-al & SA \\
\cline { 2 - 8 } & $\mathrm{CCi}$ & DA & L & DA & L & A & C \\
\cline { 2 - 8 } & $\mathrm{uCu}$ & DA & L & DA & L & Pre-pal & SA \\
\hline \multirow{3}{*}{ M5 } & $\mathrm{aCa}$ & DA & Al & DA & L & Post-al & SA \\
\cline { 2 - 8 } & $\mathrm{iCi}$ & DA & Al & DA & L & A & C \\
\cline { 2 - 8 } & $\mathrm{uCu}$ & DA & Al & DA & L & Post-al & SA \\
\hline \multirow{3}{*}{ M6 } & $\mathrm{aCa}$ & DA & A & DA & L & A & C \\
\cline { 2 - 8 } & $\mathrm{iCi}$ & DA & A & DA & L & A & C \\
\cline { 2 - 7 } & $\mathrm{uCu}$ & DA & A & DA & L & Post-al & C \\
\hline
\end{tabular}

Our study also confirms that the articulatory variations exist inside the retroflex consonant class (Ladefoged and Bhaskararao 1983, Ladefoged and Maddieson 1996). This variation is not just between different speakers but within the same speaker, more often due to vocalic environment.

\section{Conclusion}

The present study based on direct palatography and linguography tried to examine the different places of articulation and the lingual configuration of the Nepali coronal stops. We found that the articulatory descriptions of dentals and affricates agree with Pokharel's claim whereas retroflex consonant types show a different scenario from that of his analysis. Unlike Pokharel, we observed a large spectrum of retroflex consonants in Nepali. These variations (cacuminal (rim) and retroflexion) exist at the inter-speaker level as well as the intra-speaker level (vocalic contextual variation). This confirms that both types of production represent the same phonological category, i.e. retroflex. There is no language in the world that possesses two different types, i.e. cacuminal type and retroflex type, causing two different phonological categories in the sense presented by Hála's (Hála’s 1964).

Though direct palatography and linguography give us many valid arguments to support the present claim, it is however necessary to use other more precise and dynamic investigation methods such as the ultrasound method, MRI, EMMA. Though Kochetov and Pouplier took a single speaker, their recent work based on ultrasound of Nepali stops is quite promising (Kochetov, Pouplier and Truong 2013). Further sophisticated investigation is required and with more number of participants.

\section{Acknowledgement}

I am grateful to Cécile Fougeron and Annie Rialland for comments. I would like to thank Isabelle Khatiwada for her support and encouragement and Tulsi Upadhyaya for valuable help on a draft version of this paper.

References

Bandhu, Chura Mani, Ballabh Mani Dahal, Andreas Holzhausen and Austin Hale. 1971. Nepali Segmental Phonology. Katmandu: SIL \& Tribhuvan University. 
Khatiwada / 29

Bhat, Dharbe Narayana S. 1973. Retroflexion: an areal feature. Working Papers on Language Universals. Stanford University 13. 27-67.

Catford, John C. 1977. Fundamental problems in phonetics. Indiana University Press.

Clements, Georges Nick. 2009. The role of features in speech sound inventories. In Eric Raimy and Charles Cairns (eds.) Contemporary Views on Architecture and Representations in Phonological Theory. 19-68. Cambridge, MA: MIT Press.

Clements Georges Nick. 2006. Feature organization. In R. E. Asher (ed.) The Encyclopedia of Language and Linguistics ( $2^{\text {nd }}$ edn.) vol. 4. 433-441. Oxford: Elsevier Limited.

Firth, John R. 1948. Word-palatograms and articulation. Bulletin of School of Oriental and African Studies, 12. 857-864.

Hála, Bohuslav. 1964. Apical, cacuminal, rétroflexe, coronal, dorsal. Phonetica, 11.186-195.

Khatiwada, Rajesh. 2009. Nepali. Journal of International Phonetic Association, 39(3). 373-380.

Khatiwada, Rajesh. 2014. Questions de phonologie et phonétique en népalais: la rétroflexion et la double corrélation de voisement et d'aspiration. Paris: Université Sorbonne Nouvelle PhD. dissertation.

Kochetov Alexei, Pouplier Marianne and Truong Sarah. 2013. A preliminary ultrasound study of Nepali lingual articulations. Proceedings of Meetings on Acoustics ICA 2013, Montréal. poster session, online paper https://works.bepress.com/alexei kochetov/35/).

Ladefoged, Peter and Peri Bhaskararao. 1983. Non-quantal aspects of consonant production: a study of retroflex consonants. Journal of phonetics 11(3). 291-302.

Ladefoged, Peter and Maddieson, Ian. 1996. The Sounds of the World's Languages. Blackwell.

Ladefoged, Peter. 2003. Phonetic data analysis: an introduction to fieldwork and instrumental techniques. Oxford: Blackwell.

Léon, Pierre 1992. Phonétisme et Prononciations du français. Paris: Nathan.

Marchal, Alain. 1988. La palatographie. Paris: Edition du CNRS.

Pokharel, Madhav Prasad. 1989. Experimental analysis of Nepali sound system. Pune: Deccan College $\mathrm{PhD}$ dissertation.

Poon, Pamela G. and Mateer Catherine A. 1985. A Study of VOT in Nepali Stop Consonants. Phonetica 42(1). 39-47. 